\title{
Evaluation of antibacterial effect of Eucalyptus and ginger on dentinal tubules Enterococcus faecalis in the presence of smear layer
}

\author{
Samira Shahsiah, ${ }^{1 *}$ Eskandar Moghimipour, ${ }^{2}$ Nooshin Shamsizadeh ${ }^{3}$ and Azardokht Khosravi ${ }^{4}$ \\ ${ }^{1}$ Department of Endodontics, Faculty of Dentistry, Ahvaz Jundishapur University of Medical Sciences, \\ Ahvaz, Iran \\ ${ }^{2}$ Medicinal Plant Research Center, Faculty of Pharmacy, Ahvaz Jundishapur University of Medical Sciences, \\ Ahvaz, Iran \\ ${ }^{3}$ Dentist \\ ${ }^{4}$ Professor of Clinical Microbiology, Ahvaz Jundishapur Univesity of Medical Sciences, Ahvaz, Iran
}

\begin{abstract}
Enterococcus faecalis is a resistant microorganism and plays an important role in root canal treatment failure. One of the most critical steps in root canal treatment is chemical cleaning of the root canal with endodontic irrigation solutions. The most commonly used solution is Sodium hypochlorite which in spite of its broad antimicrobial activity, has many disadvantages. Therefore, this study was designed to evaluate the antibacterial effect of eucalyptus and ginger on dentinal tubules Enterococcus faecalis in the presence of smear layer. In this study dentin cylinders from 80 single rooted human teeth were prepared and contaminated with Enterococcus faecalis with smear layer created in each dentin disk. Experimental groups were as follows: Group 1: Sodium hypochlorite 5.25\%, Group 2: ginger extract, Group 3: eucalyptus extract, Group 4: Normal saline (positive control), Group 5: sterile cylinders. Then dentin chips were collected from three different depths of dentin including 0.1,0.2 and 0.3 millimeters. Optical density comparison of different experimental groups showed that there is a significant difference between groups in 0.1 and 0.2 millimeters depth $(\mathrm{p}<0.01)$, however no significant difference in 0.3 millimeters depth was obtained. Antimicrobial efficacy of eucalyptus and Sodium hypochlorite in the presence of smear layer showed no significant differences, while this effect was weaker with ginger compared to Sodium hypochlorite.
\end{abstract}

KEY WORDS: ENTEROCOCCUS FAECALIS, SMEAR LAYER, EUCALYPTUS, GINGER

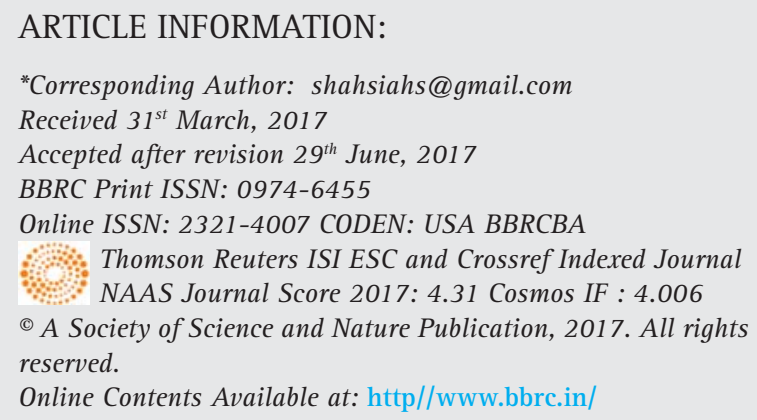




\section{INTRODUCTION}

Today different in canal detergents are used. The most popular one is sodium hypochlorite (homemade bleach). Main advantage of this material is solving necrotic tissue and its anti-microbial properties against wide range of micro-organisms such as Enterococcus faecalis. This material has some disadvantages too which include unpleasant smell and taste, toxicity during contact with pre radicular tissues, removing cloth's color, and capacity of metal corrosion (Torabinejad and Walton 2003; Gulve and Gulve 2010). Studies indicated that sodium hypochlorite has very less ability for removing smear layer. In addition, overusing this material causes reduction of dentinal elasticity strength (Hargreaves 2011).

We selected herbals for this research because of following reasons: Eucalyptus (which out of them Eucalyptus camaldulensis is most popular in Iran) and ginger are found in Iran region, there is no need to import this medicine from other countries, providing their effective concentrate has less price than chemical medicine, in compare to chemical medicine, these are more adaptive to natural environment of the body and has less unfavorable effect. No research has so far made about investigating this material as a detergent in canal at the presence of dentine and smear layer so there is need to research in this case. Historically, numerous combinations of aqueous solution are recommended as root canal detergents; including ineffective sodium chloride (saline) and so toxic and allergist biocids such as formaldehyde (Zehnder 2006).

There are different factors including numbers and diameter of dentinal tubules, sclerotic dentin, and also smear layer can affect dentine permeability and can avoid penetration of anti-microbial materials to dentinal tubules. During preparation of canal walls, some parts of dentinal wall which has contact with tools are covered by one smear layer (Hargreaves and et al, 2011; McCombEand et al, 1976). Smear layer is amorf, granular and disordered that is made from minerals such as dentianls and organic materials including pulp remnants, odontoblastic excrescence, suliva, and blood cells (Kakehashi and et al, 1965; Gwinnett 1984). (Figure 1).

Maekawa et al performed a research in 2013 in Brazil. They investigated effect of ginger and propolis 1 concentrate on some microorganisms in canal and endotoxin. According to the results, researchers recommended that propolis and ginger concentrate in combination with calcium hydroxide can be used as a medicine in alternative canal although there is need more studies on biocompatibility, chemical interactions of these materials and their clinical effects to be made so their use in endodontic treatment is approved. In another study of Martos et al in 2012 in Brazil, they considered anti-microbial activities of chloroform solution, eucalyptus oil essence, and orange oil essence lonely and also with Cetrimide in $0.05 \%, 0.1 \%, 0.2 \%, 0.3 \%$ densities. These researchers observed that biofilm reduction in orange oil and eucalyptus oil in 2 minutes indicated no significant difference; however, biofilm removal percent by orange oil in 5 minutes was more than eucalyptus oil.

Sharifian et al (2011) in Tehran performed a research in order to investigating anti-microbial properties of lime on Enterococcus faecalis in dentinal tubules in presence of smear layer on 140 dentinal cylinder provided from central incisor of cow. These researchers concluded that

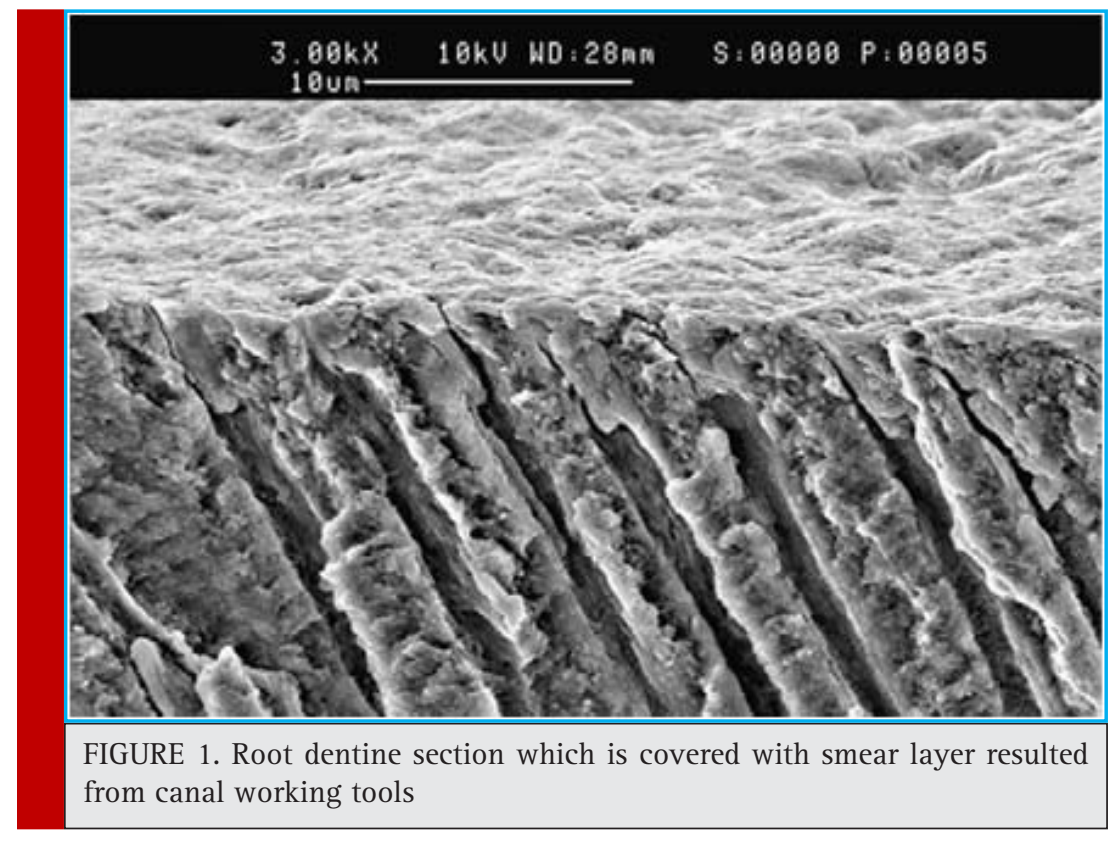


at the presence of smear layer, anti-microbial properties of lime was less than $\mathrm{NaOCl}$ while there was no difference between anti-microbial properties of lime skin and $\mathrm{NaOCl}$. Abdul Rahman et al in 2010 studied anti-microbial and bio chemical properties of food flavors in meat products. In this experiment, Disk diffusion method was used and it was indicated that cinnamon is the most effective flavor against all under studied micro-organisms except micrococcus luteus. In addition, ginger had anti-microbial activity against Enterococcus faecalis.

Gulve et al.,( 2010 )from India, managed study for comparing invitro anti-microbial properties of ginger concentrate 2\% sodium hypochlorite against Enterococcus faecalis on 18 growth medium by Agar diffusion. These two researchers observed that ginger concentrate significantly avoid bacteria's growth in compare to sodium hypochlorite. This study aimed at finding better alternative for sodium hypochlorite as a relative ideal root canal detergent. Thus, by aim of determining antimicrobial properties of eucalyptus concentrate - ginger concentrate- sodium hypochlorite, and 5.25\%- normal saline against Enterococcus faecalis at presence of smear layer in $0.1,0.2$ and 0.3 millimeter depth of dentine and comparing anti-microbial properties of eucalyptus concentrate - ginger concentrate- sodium hypochlorite and 5.25\% -normal saline in 0.1, 0.2 and 0.3 millimeter depth of dentine at presence of smear layer.At the following we will discuss materials and methods of collecting data, and collecting samples. Then in section 3 we will explain research results and statistical tests, in addition to results of the test and finally we explained the conclusion.

\section{MATERIALS AND METHODS}

In this study, in order to determining of eucalyptus concentrate - ginger concentrate - 5.25\% sodium hypochlorite- normal saline against enterococcus faecalis in 0.1 , 0.2 and 0.3 milliliter depth from dentine at the presence of smear layer.We selected 80 human teeth which were withdrawn due to different diseases including periodontal, orthodontia, dental corruption were selected from therapeutical centers in Ahvaz. These single root teeth have maxilar anseizure and mandible premolars. After withdrawn of these teeth, tissues connected to outer surface of root were separated with one court. Then in order to disinfection of teeth surface, they put in 2.5\% sodium hypochlorite, and they were kept in steal normal saline at the room temperature. Eucalyptus leaves, 70\% ethanol, dried rhizome of ginger, stilled water, standard strain of Enterococcus faecalis, growth medium BHI Broth (Merck-Germany), growth medium of BHI Agar (Merck-Germany), laboratory tube, microbial cultivation plate, cotton, gloves, 15 milliliter falcon tube (Maxell-
China), sampler (Trasnferpette-Germany), head sampler, 5.25\% sodium hypochlorite (Golrang-Iran), laboratory Handpiece (NSK-Japan), coal disk, medin broach (ManiJapan), number 4Gates-Glidden drills(Mani- Japan), nail polish, aluminum foil, self-cure acryl (Acro Pars-Iran), EDTA17\% (Cerkamed-Poland), needle gauge 23.

In order to provide plant concentrate, maceration method was used (Martos j, et al, 2013). For providing detergent, dried concentrate obtained from freezer drier were solve into stilled water slowly until a homogenous solution. Mass concentration for ginger solution was calculated equaled to $\mathrm{gr} / \mathrm{ml} 0.51$ and for eucalyptus concentrate solution equled to gr/ml0.57. then these detergents were transferred to sanitary-therapeutic center in Golestan Hospital of Ahvaz and then they were sterile ed with X-ray (Shalaby E. A, 2011). Standard ndard strain of 29212 ATCC $^{1}$ Enterococcus faecalis bacteria was provided from Pastor Institute of Iran in Tehran. Brain heart infusion broth steal Growth medium (Merck-Germany) was prepared and added into Lyophilizated in order to solve it completely. Then it was cultivating on BHI Agar growth medium (Merck-Germany) and they were incubated in aerobic condition in $\mathrm{C}^{\circ} 37$ for 24 hours. Then by biochemical tests for bacteria identification (smear provision, PYR test, Bile esculin, Catalaz) we assured from its purity. So 24 hours colonies provided fro,m pure enterococcus faecalis. For providing bacteria suspension, bacteria clonies were taken from solid growth medium and solved in a tube with sterile BHI Broth and then we obtained a suspension with turbidity Mc farland (cfu/ml 3x

Samples withdrawn from autoclave were opened under laminar airflow hood and they were all inoculated by 20-10 micro litter bacteria suspension of enterococcus faecalis with strain 1 of Mc Farland (cfu/ml 3x except negative control group. Then cylinders were covered with a lid made from sterile aluminum paper and growth medium with bacteria were added into each cylinder every two days by sample (Trasnferpette-Germany) and trough sterile head sampler. In negative control group, sterile BHI Broth growth medium were added into teeth. This was repeated 4 weeks for providing maximum penetration of bacteria into dentinal tubules (Shabahang $\mathrm{S}$ and Torabinejad M, 2003; Ahangari Z, et al, 2008) and the samples were incubated in aerobic condition and in $37^{\circ} \mathrm{C}$.

When inoculation ended, I order to make sure of micro-organisms penetration into dentinal tubules, 10 samples were randomly selected out of samples. Then acrylic layer were removed from lumen of these samples and patterned by low speed and Gates Gilden (Mani-Japan) number 5 (o.1 milliliter depth), Gates

${ }^{1}$ American type culture collection 
Gilden (Mani-Japan) number 6 (0.2 milliliter depth) and pisormer (Mani-Japan) number 6 (0.3 milliliter depth) from dentine.

Provided dentine chips from different dentinal sections were placed separately in 15 milliliter falcon tubes (Maxell-China) with 3 milliliter sterile BHI Broth and were incubated 48 hours in $37 \mathrm{C}^{\circ}$ temperature. Then, out of 30 mentioned tube some samples were cultivated on plates with BHI Agar and were incubated in aerobic condition and in $37^{\circ} \mathrm{C}$ temperature. After incubation end, micro-organisms identification test in order to be sure about that bacteria are single strain and its penetration in 3 depths.

In other samples, smear layer was created by sterile hedstroms number 50 (Mani-Japan). In a way that hedstrom number 50 were withdrawn three times and by push and pull movement on canal wall. In order to avoid pollution of environment implying to Luman cylinders each hedstrom were changed after one time use.

In next step, samples in group 1,2,3 and 4 were washed separately by 5 milliliter sterile syringe (HomaSorang-Iran) and 23 needles with gauge and from negative control group, patterning was made in 3 depth. Washing syringe were changed for each sample after using them once in order to minimize environmental pollution. Group washing was made as follow:

Group 1: 2 milliliter Naocl 5.25\% in each sample for 20 minutes.

Group 2: 2 milliliter ginger concentrate with $\mathrm{mg} /$ ml127.5 density in each sample for 20 minutes. Group 3: 2 milliliter eucalyptus concentrate with $\mathrm{mg} / \mathrm{ml} 17.8$ density in each sample for 20 minutes. Group 4 (positive control): 2 milliliter sterile normal saline in each sample for 20 minutes.

Group 5 (negative control): washing was not made in this group. In order to be confidant about lack of cylinder pollution penetration into another bacteria and test correction was patterned except Enterococcus faecalis.

When acrylic layer washing, cylinders were remove from lumen of then dentine sampling was performed by low speed and Gates Gilden (Mani-Japan) number 5 drills (o.1 milliliter depth ), Gates Gilden (Mani-Japan) number 6 drills (0.2 milliliter depth) and pisormer (ManiJapan) number 6 (0.3 milliliter depth) from dentine. In a way that 15 milliliter falcon tubes (Maxell-China) with 3 milliliter sterile BHI Broth was prepared and dentine chips obtained from shaving were transferred into these tubes in each step from dentine cylinders.

It should be mentioned that tubes were incubated 48 hours in $37 \mathrm{C}^{\circ}$ temperature. Then, out of 30 mentioned tube some samples were cultivated on plates with BHI Agar and were incubated in aerobic condition and in $37^{\circ} \mathrm{C}$ temperature. After incubation end, micro-organisms identification test in order to be sure about that bacteria are single strain and its penetration in 3 depths.

In order to measure strain from microbial growth, 2.5 milliliter was extracted from BHI Broth in tubes with dentinal chips removed from incubator and its optical density was studied by Spectrophotometer (WPA-biowave2-USA) 540 nano-meter in wave length. Optical density of groups under experiment and positive control groups were compared together.

\section{RESULTS AND DISCUSSION}

Optical density related to experimental groups in three depths $(0.1,0.2,0.3)$ milliliter from dentine was measured by Spectrophotometer (Biochrom WPA - USA). Mean and standard deviation of OD were mustered for different depths in table 1.

Comparing experimental groups considering OD rate in 3 measured dentinal depths was performed based on statistical analysis of One-way ANOVA and SPSS software.

According to table 2, and One-way ANOVA in 0.1 millimeter of dentine there was significant difference between under studied groups $(\mathrm{p}<0.01)$. in addition, in 0.2 millimeter of dentine there was significant difference between under studied groups $(p<0.01)$. But in 0.3 millimeter of dentine there was no significant difference between under studied groups.

Shortly, comparing different groups with considering OD in each depth by one-way ANOVA analysis indicated that there is significant difference between groups

\begin{tabular}{|l|c|c|l|}
\hline \multicolumn{4}{|l|}{ Table 1. Mean \pm standards deviation of optical density of provided filings from three dentinal depth under study } \\
\hline $\begin{array}{l}\text { Mean }( \pm \text { standards deviation) } \\
0.3 \text { millimeter depth }\end{array}$ & $\begin{array}{c}\text { Mean }( \pm \text { standards deviation) } \\
0.2 \text { millimeter depth }\end{array}$ & $\begin{array}{c}\text { Mean }( \pm \text { standards deviation) } \\
0.1 \text { millimeter depth }\end{array}$ & Detergent solutions \\
\hline$\left(0.08_{ \pm}\right) 0.23$ & $\left(0.11_{ \pm}\right) 0.22$ & $(0.04 \pm) 0.016$ Sodium hypochlorite & 1- Sodium hypochlorite \\
\hline$(0.25 \pm) 0.34$ & $\left(0.21_{ \pm}\right) 0.34$ & $(0.07 \pm) 0.24$ & 2- ginger concentrate \\
\hline$\left(0.21_{ \pm}\right) 0.26$ & $(0.04 \pm) 0.21$ & $(0.04 \pm) 0.18$ & 3- eucalyptus concentrate \\
\hline$\left(0.08_{ \pm}\right) 0.40$ & $\left(0.00_{ \pm}\right) 0.46$ & $(0.07 \pm) 0.41$ & $\begin{array}{l}\text { 4- Normal saline } \\
\text { (positive control) }\end{array}$ \\
\hline
\end{tabular}




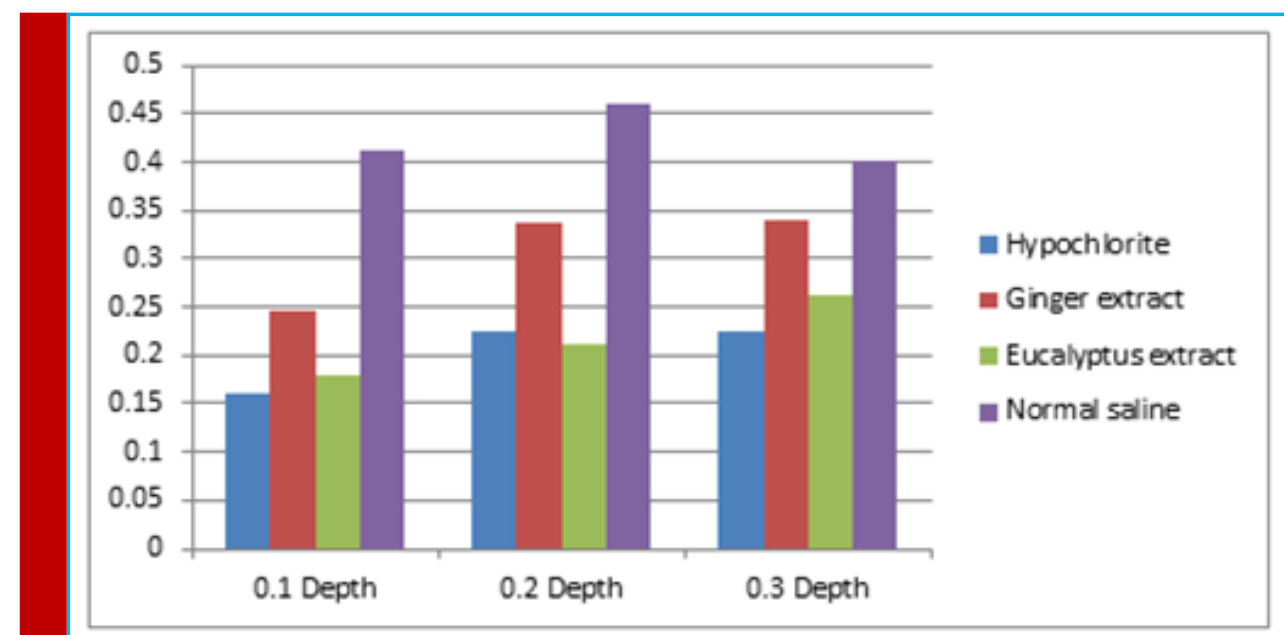

DIAGRAM 1. Mean of optical density of provided filings from three dentinal depth under study

\begin{tabular}{|l|l|l|l|l|l|l|}
\hline \multicolumn{6}{|c|}{ Table 2. comparing OD between groups under study in 0.1 millimeter depth from dentine } \\
\hline & Depth & Sum of Squares & $\mathrm{df}$ & Mean Square & F & Sig. \\
\hline 0.1 & Between Groups & .308 & 4 & .077 & 28.084 & .000 \\
\hline & Within Groups & .178 & 65 & .003 & & \\
\hline & Total & .486 & 69 & & & \\
\hline 0.2 & Between Groups & .376 & 4 & .094 & 5.005 & .001 \\
\hline & Within Groups & 1.220 & 65 & .019 & & \\
\hline & Total & 1.596 & 69 & & & \\
\hline 0.3 & Between Groups & .219 & 4 & .055 & 1.606 & .183 \\
\hline & Within Groups & 2.214 & 65 & .034 & & \\
\hline & Total & 2.433 & 69 & & & \\
\hline
\end{tabular}

Table 3. comparing pairwise OD of under study groups in 0.1 milliliter depth from dentine

\begin{tabular}{|c|c|c|c|c|c|c|c|}
\hline \multirow{2}{*}{ Depth } & \multirow{2}{*}{$\begin{array}{l}\text { (I) } \\
\text { group }\end{array}$} & \multirow{2}{*}{$\begin{array}{l}\text { (J) } \\
\text { group }\end{array}$} & \multirow{2}{*}{$\begin{array}{l}\text { Mean Difference } \\
\text { (I-J) }\end{array}$} & \multirow{2}{*}{ Std. Error } & \multirow{2}{*}{ Sig. } & \multicolumn{2}{|c|}{ 95\% Confidence Interval } \\
\hline & & & & & & Lower Bound & Upper Bound \\
\hline \multirow{6}{*}{0.1} & \multirow{3}{*}{1} & 2 & $-.085650^{*}$ & .016549 & .000 & -.11870 & -.05260 \\
\hline & & 3 & -.018150 & .016549 & .277 & -.05120 & .01490 \\
\hline & & 4 & $-.251650^{*}$ & .026166 & .000 & -.30391 & -.19939 \\
\hline & \multirow{3}{*}{2} & 1 & $.085650^{*}$ & .016549 & .000 & .05260 & .11870 \\
\hline & & 3 & $.067500^{*}$ & .016549 & .000 & .03445 & .10055 \\
\hline & & 4 & $-.166000^{*}$ & .026166 & .000 & -.21826 & -.11374 \\
\hline & \multirow{3}{*}{3} & 1 & .018150 & .016549 & .277 & -.01490 & .05120 \\
\hline & & 2 & $-.067500^{*}$ & .016549 & .000 & -.10055 & -.03445 \\
\hline & & 4 & $-.233500^{*}$ & .026166 & .000 & -.28576 & -.18124 \\
\hline & \multirow{3}{*}{4} & 1 & $.251650^{*}$ & .026166 & .000 & .19939 & .30391 \\
\hline & & 2 & $.166000^{*}$ & .026166 & .000 & .11374 & .21826 \\
\hline & & 3 & $.233500^{*}$ & .026166 & .000 & .18124 & .28576 \\
\hline
\end{tabular}


under study in 0.1 and 0.2 milliliter depth from dentine $(\mathrm{p}<0.01)$. but this difference in 0.3 depth is not significant. According to post hoc test of Fisher's least significant differences

(LSD) with 95\% confidence we performed comparing groups as pairwise in each depth. Group numbering is as follow:

Group number 1: 5.25\% sodium hypochlorite Group number 2: ginger concentrate

Group number 3: eucalyptus concentrate

Group number 4: normal saline (positive control)

According to post hoc test and table 3 in 0.1 milliliter depth of dentine, anti-microbial effect of 5.25\% sodium hypochlorite was significantly better that ginger concentrate and eucalyptus concentrate $(p<0.01)$. While there was no significant difference between 5.25\% sodium hypochlorite and eucalyptus concentrate.

In addition comparing ginger concentrate and eucalyptus concentrate indicated that in 0.1 milliliter depth of dentine, there is no significant difference between these two concentrate anti- microbial effect $(\mathrm{p}<0.01)$. and eucalyptus concentrate had better anti- microbial effect on enterococcus faecalis in dentinal tubules at the presence of smear layer.

In 0.1 milliliter depth of dentine, anti- microbial effect of $5.25 \%$ sodium hypochlorite, ginger concentrate and eucalyptus concentrate was significantly better than normal saline $(\mathrm{p}<0.01)$.

According to post hoc test and table 4 in in 0.2 milliliter depth of dentine, 5.25\% sodium hypochlorite was significantly better that ginger concentrate and normal saline $(\mathrm{p}<0.02)$. While there was no significant difference between 5.25\% sodium hypochlorite and eucalyptus concentrate.
In addition comparing ginger concentrate and eucalyptus concentrate indicated that in 0.2 milliliter depth of anti- microbial effect dentine there is no significant difference $(p<0.01)$. and eucalyptus concentrate has better anti- microbial effect on enterococcus faecalis in dentinal tubules at the presence of smear layer.

In 02 milliliter depth of dentine, anti- microbial effect of 5.25\% sodium hypochlorite and eucalyptus concentrate was significantly better that normal saline $(p<0.01)$ while there was no significant difference between antimicrobial effect of ginger concentrate and normal saline.

According to post hoc test and table 5 in 0.3 milliliter depth of dentine, there is no significant difference in anti-microbial effect of 5.25\% sodium hypochlorite, ginger concentrate, eucalyptus concentrate , and normal saline was significantly better that ginger concentrate and normal saline $(\mathrm{p}<0.02)$. While there was no significant difference between 5.25\% sodium hypochlorite and eucalyptus concentrate.

\section{3-1 results of growth and lack of growth after applying canal detergents}

In this study, in addition to measure optical density of all environments under experiment, some samples were cultivated as what is described in methodology. Growth and lack of growth of bacteria on growth medium was reported in each dentinal cylinder. Results of samples cultivation was reported in table 8.

Table 8 indicates that:

In group 1(5.25\% sodium hypochlorite) 30\% canals had alive batteries.

In group 2( ginger concentrate ) 45\% canals had alive batteries.

In group 3( eucalyptus concentrate ) 20\% canals had alive batteries.

\begin{tabular}{|c|c|c|c|c|c|c|c|}
\hline \multirow{2}{*}{ Depth } & \multirow{2}{*}{$\begin{array}{l}\text { (I) } \\
\text { group }\end{array}$} & \multirow{2}{*}{$\begin{array}{l}\text { (J) } \\
\text { group }\end{array}$} & \multirow{2}{*}{$\begin{array}{l}\text { Mean Difference } \\
\text { (I-J) }\end{array}$} & \multirow{2}{*}{ Std. Error } & \multirow{2}{*}{ Sig. } & \multicolumn{2}{|c|}{ 95\% Confidence Interval } \\
\hline & & & & & & Lower Bound & Upper Bound \\
\hline \multirow{3}{*}{0.2} & \multirow{3}{*}{1} & 2 & $-.111750^{*}$ & .043327 & .012 & -.19828 & -.02522 \\
\hline & & 3 & .013000 & .043327 & .765 & -.07353 & .09953 \\
\hline & & 4 & $-.234400^{*}$ & .068507 & .001 & -.37122 & -.09758 \\
\hline & \multirow{3}{*}{2} & 1 & $.111750^{*}$ & .043327 & .012 & .02522 & .19828 \\
\hline & & 3 & $.124750^{*}$ & .043327 & .005 & .03822 & .21128 \\
\hline & & 4 & -.122650 & .068507 & .078 & -.25947 & .01417 \\
\hline & \multirow{3}{*}{3} & 1 & -.013000 & .043327 & .765 & -.09953 & .07353 \\
\hline & & 2 & $-.124750^{*}$ & .043327 & .005 & -.21128 & -.03822 \\
\hline & & 4 & $-.247400^{*}$ & .068507 & .001 & -.38422 & -.11058 \\
\hline & \multirow{3}{*}{4} & 1 & $.234400^{*}$ & .068507 & .001 & .09758 & .37122 \\
\hline & & 2 & .122650 & .068507 & .078 & -.01417 & .25947 \\
\hline & & 3 & $.247400^{*}$ & .068507 & .001 & .11058 & .38422 \\
\hline
\end{tabular}


Table 5. comparing pairwise OD of under study groups in 0.3 milliliter depth from dentine

\begin{tabular}{|c|c|c|c|c|c|c|c|}
\hline \multirow{2}{*}{ Depth } & \multirow{2}{*}{$\begin{array}{l}\text { (I) } \\
\text { group }\end{array}$} & \multirow{2}{*}{$\begin{array}{l}\text { (J) } \\
\text { group }\end{array}$} & \multirow{2}{*}{$\begin{array}{l}\text { Mean Difference } \\
\text { (I-J) }\end{array}$} & \multirow{2}{*}{ Std. Error } & \multirow{2}{*}{ Sig. } & \multicolumn{2}{|c|}{ 95\% Confidence Interval } \\
\hline & & & & & & Lower Bound & Upper Bound \\
\hline \multirow{4}{*}{0.3} & \multirow{4}{*}{1} & 2 & -.114500 & .058369 & .054 & -.23107 & .00207 \\
\hline & & 3 & -.036700 & .058369 & .532 & -.15327 & .07987 \\
\hline & & 4 & -.176650 & .092289 & .060 & -.36096 & .00766 \\
\hline & & 5 & -.017050 & .092289 & .854 & -.20136 & .16726 \\
\hline & \multirow{4}{*}{2} & 1 & .114500 & .058369 & .054 & -.00207 & .23107 \\
\hline & & 3 & .077800 & .058369 & .187 & -.03877 & .19437 \\
\hline & & 4 & -.062150 & .092289 & .503 & -.24646 & .12216 \\
\hline & & 5 & .097450 & .092289 & .295 & -.08686 & .28176 \\
\hline & \multirow{4}{*}{3} & 1 & .036700 & .058369 & .532 & -.07987 & .15327 \\
\hline & & 2 & -.077800 & .058369 & .187 & -.19437 & .03877 \\
\hline & & 4 & -.139950 & .092289 & .134 & -.32426 & .04436 \\
\hline & & 5 & .019650 & .092289 & .832 & -.16466 & .20396 \\
\hline & \multirow{4}{*}{4} & 1 & .176650 & .092289 & .060 & -.00766 & .36096 \\
\hline & & 2 & .062150 & .092289 & .503 & -.12216 & .24646 \\
\hline & & 3 & .139950 & .092289 & .134 & -.04436 & .32426 \\
\hline & & 5 & .159600 & .116737 & .176 & -.07354 & .39274 \\
\hline
\end{tabular}

In group 4( normal saline (positive control ) 100\% canals had alive batteries.

In group 5( negative control ) no canals had alive batteries.

Group number 1: 5.25\% sodium hypochlorite Group number 2: ginger concentrate Group number 3: eucalyptus concentrate Group number 4: normal saline (positive control)

Many studies have been made so far on anti-microbial properties of plant (Karlović et al, 2000; Hammer et al, 1999; Rahman et al, 2010; Adeniyi et al, 2006; Shalaby et al, 2011; Dulger and Gonaz 2004) and there are many studies that considered anti-microbial properties of plant as detergents (Gulve and Gulve 2010; Sharifian et al, 2011; Maekawa et al 1013). It is clear that this topic is very important. Consequently, in many researches, no groups under study were able to remove bacteria of canal at the presence of smear layer. Normal saline groups indicated 100\% growth. This material has no inhibition properties against Enterococcus faecalis and its effect on existing micro-organisms in canal happens through mechanical act. In sterile dentinal cylinder (negative control), no growth was observed which indicates that there is no pollution in environment and applied tools so accuracy of performance was approved. Anti- microbial effect of Eucalyptus camaldulensis concentrate on enterococcus faecalis (ATCC29212) in cylinders provided from human teeth at the presence of smear layer, with 5.25\% sodium hypochlorite has no significant difference. In addition, anti- microbial effect of Zingiber officinale on Enterococcus faecalis (ATCC29212) in cylinders provided from human teeth at the presence of smear layer is weaker than $5.25 \%$ sodium hypochlorite.

\begin{tabular}{|l|l|l|l|}
\hline \multicolumn{5}{|l|}{ Table 6. numbers of samples with bacterial growth } \\
\hline Lack of growth & growth & numbers of samples & Group \\
\hline 14 & 6 & 20 & $5.25 \%$ sodium hypochlorite \\
\hline 11 & 9 & 20 & Gin \\
\hline 16 & 4 & 20 & eucalyptus concentrate \\
\hline 0 & 5 & 5 & Normal saline (positive control) \\
\hline 5 & 0 & 5 & $\begin{array}{l}\text { Dentinal cylinder (negative } \\
\text { control) }\end{array}$ \\
\hline
\end{tabular}




\section{REFERENCES}

Abubakar EMM. (2010). Antibacterial potential of crude leaf extract of Eucalyptus camaldulensis against some pathogenic bacteria. Afr J Plant Sci; 4(6):202-209.

Adeniyi BA, Odufowoke R0, Olaleye SB. (2006). Antibacterial and gastroprotective properties of Eucalyptus torelliana (myrtaceae) crude extract. Int J Pharmacol; 2:362-365.

Ahangari Z. (2008). Antimicrobial activity of three root canal irrigants on Enterococcus faecalis: An in vitro study. Iran Endod J; 3(2):33-37.

Ali BH, Blunden G, Tanira MO, Nemmar A. (2008). Some phytochemical, pharmacological and toxicological properties of Ginger (Zingiber officinale roscoe): a review of recent research. Food Chem Toxicol; 46(2):409-420.

Chanadarana H, Baluja S, Chanda SV. (2005). Comparison of antimicrobial activities of selected spices of Zingiberaceae family and some synthetic compounds. Turk J Biol. 29:83-97.

Dulger B, Gonaz A. (2004). Antimicrobial activity of certain plants used in Turkish traditional medicine. Asian journal of plant sciences. 3(1):104-107.

Forbes BA, Sahm DF, Weissfeld AS. (2007). Bailey and Scott's diagnostic microbiology. 12th ed. St.Louis:Mosby.

Foschi F, Cavrini F. (2005). Detection of bacteria in endodontic samples by polymerase chain reaction assay and association with defined clinical signs in Italian patients. Oral Microbiol Immunol; 20(5):289-295.

Fux CA., Shirtliff M. (2005). Can laboratory reference strains mirror "real-world" pathogenesis. Trends MIcrobiol. 13:58-63.

Gulve MM, Gulve ND. (2010). Comparison of antimicrobial efficacy of ginger extract and 2\% Sodium hypochlorite against Enterococcuc faecalis using Agar diffusion method. Int Dent Assoc; 4(10):347-349.

Gwinnett AJ. (1984). smear layer: morphological considerations. Oper Dent Suppl 3:2-12.

Hammer K.A. (1999). Antimicrobial activity of essential oils and other plant extracts. J appl microbial. 86:985-990.

Hargreaves KM, Cohen S, Berman LH. (2011). Pathways of the pulp. 10th ed.St Louis:Catherine Jackson.

Kakehashi S. Stanley HR, Fitzgerald RJ. (1965). The effects of surgical exposures of dental pulp in germ free and conventional laboratory rats. Oral Surg; 26:340-349.

Karlović Z. (2000). Antimicrobial activity of Halothane, Eucalyptol and Orange oil. Acta stomatol Croat; 34(3):307.

Keskin D, Toroglu S. (2011). Studies on antimicrobial activities of solvent extracts of different spices.J Environ Biol; 32:251-256.

Maekawa LE. (2013). Effect of Zingiber officinale and Propolis on microorganisms and endotoxins in root canals. J Appl Oral Sci. Jan-Feb; 21(1):25-31.

Martos j, Luque CMF. (2013). Antimicrobial activity of essential oils and Chloroform alone and combined with Cetrimide against Enterococcus faecalis biofilm. Eur J Microbiol Immunol. 3(1):44-48.

McComb D, Smith DC, Beagrie GS. (1976). The results of in vivo endodontic chemomechanical instrumentation-a scanning electron microscopic study. J Br Endod Soc; 9:11-18.

Murad CF. (2012). Antimicrobial activity of Sodium hypochlorite, Chlorhexidine and MTAD against Enterococcus faecalis biofilm on human dentin matrix in vitro. RSBO 9(2):143150.

Onçağ 0, Hosgör M, Hilmioğlu S, Zekioğlu 0, Eronat C, Burhanoğlu D. (2003). Comparison of antibacterial and toxic effects of various root canal irrigants. Int Endod J. 36(6):423-32.

Peciuliene V, Reynaud AH, Balciuniene I, Haapasalo M. (2001). Isolation of yeast and enteric bacteria in root-filled teeth with chronic apical periodontitis. Int Endod J. 34(6): 429-34.

Rahman MSA, Thangaraj S, Salique SM, Khan KF, Natheer SE. (2010). Antimicrobial and biochemical analysis of some spices extract against food spoilage pathogens. Int J Food Safe. 12:71-75.

Retamozo B, Shabahang S, Johnson N, Aprecio RM, Torabinejad M. (2010). Minimum contact time and concentration OD Sodium hypochlorite required to eliminate Enterococcus faecalis. J Endod. 36(3):520-3.

Shabahang S, Torabinejad M. (2003). Effect of MTAD on Enterococcus faecalis-contaminated root canals of extracted human teeth. J Endod; 29(9):576-579.

Shalaby EA, Nasr NF, El Sherief SM. (2011). An in vitro study of the antimicrobial and antioxidant efficacy of some nature essential oils. Planta Med; 5(6):922-931.

Sharifian MR. (2011). Antimicrobial effect of Citrus aurantifolia extract on Enterococcus faecalis within the dentinal tubules in the presence of smear layer. J Dent Med; 24(3):148155.

Sheykhrezaei MS, Aligholi M, Biglar KH. (2004). An in-vitro evaluation of the ability of $5.25 \% \mathrm{NaOCl}$ in the elimination OD Enterococcus faecalis from root canal. Journal of dentistry, TUMS. 1(2):45-48.

Torabinejad M, Handysides R, Khademi AA, Bakland LK. (2002). Clinical implications of the smear layer in endodontics: a review, oral surg oral med oral pathol oral radiol Endod. 94(6): p 658.

Torabinejad M, Walton RE. (2008). Endodontics: principles and practice. 4th ed. St. Louis: Saunders.

Yiu CK, García-Godoy F. (2002). A nanoleakage perspective on bonding to oxidized dentin. J Dent Res; 81:628-632.

Zehnder M. (2006). Root canal irrigants. J Endod; 32(5):389398.

Zoletti GO, Siqueira JF Jr, Santos KR. (2006). Identification of Enterococcus faecalis in root-filled teeth with or without periradicular lesions by culture dependent and independent approaches. J Endod; 32(8):722-726. 